\title{
Symmetrical Dimethylarginine Outperforms CKD-EPI and MDRD-Derived eGFR for the Assessment of Renal Function in Patients with Adult Congenital Heart Disease
}

\author{
Oktay Tutarel $^{\mathrm{a}} \quad$ Agnieszka Denecke $^{\mathrm{a}, \mathrm{b}}$ Stefanie M. Bode-Böger ${ }^{\mathrm{c}}$ \\ Jens Martens-Lobenhoffer ${ }^{c}$ Bernhard Schieffer ${ }^{a}$ Mechthild Westhoff-Bleck ${ }^{a}$ \\ Jan T. Kielstein ${ }^{b}$ \\ Departments of a Cardiology and Angiology and ${ }^{b}$ Nephrology and Hypertension, Hannover Medical School, \\ Hannover, and ' Institute for Clinical Pharmacology, Otto von Guericke University, Magdeburg, Germany
}

\section{Key Words}

Adult congenital heart disease $\cdot$ Glomerular filtration rate $\cdot$

Glomerular filtration rate formula

\begin{abstract}
Background/Aims: Adults with congenital heart disease exhibit a 3-fold higher mortality in the presence of chronic kidney disease, hence assessment of renal function is crucial in this patient population. Formulas for the estimation of glomerular filtration rate (GFR) have not been evaluated in this patient population. Therefore, this study compares different markers and equations for the estimation of renal function in adults with congenital heart disease. Methods: Renal function was assessed in 102 patients using the Modification of Diet in Renal Disease (MDRD) equation, the simplified MDRD equation, the Chronic Kidney Disease Epidemiology Collaboration (CKD-EPI) equation and the Cockcroft-Gault formula. Additionally, symmetrical dimethylarginine (SDMA) was measured. Those parameters were compared to cystatin C-derived GFR using the Larsson equation. Results: GFR estimates using the original MDRD $(r=0.465, p<0.001)$ and the CKD-EPI equation $(r=0.462, p<0.001)$ showed a similar strong correlation with the cystatin C-based eGFR equation, while eGFR using the simplified MDRD equation showed a
\end{abstract}

slightly weaker correlation $(r=0.439, p<0.001)$. The Cockcroft-Gault formula showed no correlation at all to the cystatin C-based eGFR ( $r=0.144, p=0.17)$. The strongest correlation was observed for SDMA and cystatin C-based eGFR ( $r=$ $-0.552, p<0.001)$. Conclusion: GFR in adults with congenital heart disease should be estimated using the original MDRD or the CKD-EPI formula. SDMA seems to be a promising marker of renal function for this patient group.

Copyright $\odot 2010$ S. Karger AG, Basel

\section{Introduction}

Formulas for the estimation of glomerular filtration rate (GFR) have rarely been evaluated in special patient populations. Adults with congenital heart disease exhibit a 3-fold higher mortality with a moderate or severe reduction in GFR [1]. However, GFR cannot be measured by direct means but by determination of urinary clearance of filtration markers. The gold standard, inulin clearance, is cumbersome and expensive, reducing its utility in clinical practice, which holds also true for esti-

O.T. and A.D. contributed equally to this work.

\section{KARGER}

Fax +41613061234 E-Mail karger@karger.ch www.karger.com (c) 2010 S. Karger AG, Basel

$1420-4096 / 11 / 0341-0041 \$ 38.00 / 0$

Accessible online at: www.karger.com/kbr
Oktay Tutarel, MD

Department of Cardiology and Angiology

Hannover Medical School

Carl-Neuberg-Str. 1, DE-30625 Hannover (Germany)

Tel. +49511532 2532, Fax +49511532 3229, E-Mail otutarel@ hotmail.com 
mations using the clearance of radioisotopes [2]. Dimopoulus et al. [1] calculated GFR in adult patients with congenital heart disease using the Modification of Diet in Renal Disease equation (MDRD). This equation has some limitations. Its accuracy is reduced in the state of normal or slightly diminished renal function. To overcome this problem the Chronic Kidney Disease Epidemiology Collaboration (CKD-EPI) equation was recently introduced [3]. This equation is more accurate than the MDRD study equation, especially in subjects with normal or slightly impaired renal function. Also, the CKD-EPI formula has been evaluated across various study populations and clinical conditions [3].

The accuracy of these formulas in patients with cardiovascular disease has not been well substantiated [4]. Therefore, a search for new markers and equations for the assessment of renal function has begun. Lately, two markers which show promise are serum cystatin $C$ and symmetrical dimethylarginine (SDMA). Serum cystatin C concentration is a better marker of renal dysfunction (that is, reduced GFR) than plasma creatinine concentration, at least in elderly subjects with plasma creatinine concentrations within the normal range. Also SDMA, the structural isomer of the endogenous nitric oxide inhibitor asymmetric dimethylarginine, has been found to be a reliable marker of renal function [5]. This 202-Da compound was first detected in human urine [6] and seems to be exclusively eliminated by renal excretion [7]. A meta-analysis of 18 studies involving a total of 2,136 patients showed a strong correlation between SDMA and different parameters of renal function [5].

The aim of this study was to compare different markers and equations for the estimation of renal function to cystatin C-based GFR in adults with congenital heart disease.

\section{Methods}

The patients were recruited during an outpatient visit at our Adult Congenital Heart Disease Clinic. All patients in whom a venous blood sampling was feasible were eligible for this study. The study was approved by the Ethics Committee of Hannover Medical School, Hannover, Germany. All patients gave written informed consent.

The severity of the congenital heart defect was graded according to recent recommendations [8].

\section{Laboratory Methods}

Blood samples for measurement of plasma SDMA, cystatin C and routine chemistry were drawn. Blood samples were immediately cooled on ice, centrifuged at $1,500 \mathrm{~g}$ and $4^{\circ} \mathrm{C}$ for $10 \mathrm{~min}$. Supernatants were stored in $1-\mathrm{ml}$ aliquots at $-80^{\circ} \mathrm{C}$ until further use.
Plasma concentrations of SDMA were measured applying a recently developed liquid-chromatography mass-spectrometry method described elsewhere [9]. All other measurements were done with routine laboratory tests using certified assay methods.

Estimation of Kidney Function

GFR according to the Cockcroft-Gault formula [10]: Creatinine clearance $=(140-$ age $) \times($ weight in $\mathrm{kg}) / 72 \times \mathrm{Scr} \times 0.85$ (if female), where Scr is serum creatinine ( $\mathrm{mg} / \mathrm{dl})$.

GFR according to the MDRD equation [11]: GFR $=170 \times$ $[\mathrm{Scr}]^{-0.999} \times[12]^{-0.176} \times 0.762$ (if female) $\times 1.180$ (if black) $\times$ $[\mathrm{SUN}]^{-0.170} \times[\mathrm{Alb}]^{+0.318}$, where Scr is serum creatinine concentration (mg/dl), Alb is serum albumin concentration (g/dl) and SUN is serum urea nitrogen concentration $(\mathrm{mg} / \mathrm{dl})$.

GFR according to the simplified MDRD equation [12]: GFR = $186 \times \mathrm{Scr}^{-1.154} \times \operatorname{age}^{-0.203} \times 1.212$ (if black) $\times 0.742$ (if female), where $\mathrm{Scr}$ is serum creatinine $(\mathrm{mg} / \mathrm{dl})$.

GFR according to the CKD-EPI equation [3]: GFR $=141 \times$ $\min (\mathrm{Scr} / \kappa, 1)^{\alpha} \times \max (\mathrm{Scr} / \kappa, 1)^{-1.209} \times 0.993^{\text {Age }} \times 1.018$ (if female) $\times 1.159$ (if black), where Scr is serum creatinine ( $\mathrm{mg} / \mathrm{dl}), \kappa$ is 0.7 for females and 0.9 for males, $\alpha$ is -0.329 for females and -0.411 for males, min indicates the minimum of $\mathrm{Scr} / \kappa$ or 1 , and max indicates the maximum of Scr/K or 1 .

GFR according to the Larsson equation [13]: GFR $=77.24 \times$ $\mathrm{Scyc}^{-1.2623}$, where Scyc is serum cystatin C.

\section{Statistical Analysis}

We used SPSS 15.0 for statistical analysis. Continuous data are presented as means \pm standard deviation. Categorical data are presented as counts and proportions. Patient demographic and clinical characteristics were summarized as means \pm standard deviation. For correlation Pearson's correlation coefficient was calculated. The significance level was set at $\mathrm{p}<0.05$.

\section{Results}

One hundred and two patients were enrolled in our cross-sectional study. Due to incomplete data sets 5 patients were excluded and the final analysis is based on 97 patients. Table 1 shows the clinical characteristics of the study population. Overall renal function of patients with congenital heart disease was not impaired. The number of patients in the different GFR stages was as follows: 60 $90 \mathrm{ml} / \mathrm{min} / 1.73 \mathrm{~m}^{2}, 4$ patients; $>90 \mathrm{ml} / \mathrm{min} / 1.73 \mathrm{~m}^{2}, 93$ patients.

GFR estimated by the original MDRD (Pearson $r=$ $0.465, \mathrm{p}<0.001)$ and the CKD-EPI equation $(\mathrm{r}=0.462$, $\mathrm{p}<0.001)$ showed a similar strong correlation with the eGFR based on a cystatin C-based equation (fig. 1). While GFR according to the simplified MDRD equation showed a slightly weaker correlation $(r=0.439, \mathrm{p}<0.001)$, creatine clearance according to the Cockcroft-Gault formula showed no correlation at all to the cystatin C-based 
eGFR $(r=0.144, p=0.17)$. The strongest correlation was observed for SDMA and cystatin C-based eGFR ( $\mathrm{r}=$ $-0.552, \mathrm{p}<0.001)$ (fig. 1).

\section{Discussion}

In this study, GFR estimated by the CKD-EPI equation performed equally well as GFR estimated by the original MDRD equation. Both formula-based estimates of GFR were outperformed by SDMA.

The CKD-EPI equation has several advantages compared to the MDRD study equation. The later was developed by studying people with chronic kidney disease, and as such, its major limitations are imprecision and systematic underestimation of measured GFR at higher values [3]. The CKD-EPI equation has lower bias, especially at an estimated GFR greater than $60 \mathrm{ml} / \mathrm{min}$ per $1.73 \mathrm{~m}^{2}$ [3]. Further, one additional parameter needed for the MDRD study equation is albumin, while for the CKD-EPI formula only creatinine has to be measured. Therefore, the CKD-EPI equation is more cost-effective. The simplified MDRD equation used by Dimopoulos et al. [1] showed a slightly weaker correlation with the cystatin C-based GFR than the CKD-EPI equation in our study. Therefore, if a creatinine-based formula for GFR estimation is used in adults with congenital heart disease it should be the CKD-EPI equation. The Cockcroft-Gault formula-derived creatinine clearance showed no correlation with the cystatin C-based GFR, suggesting its limited practical applicability to this patient group.

SDMA showed the tightest correlation to a cystatin Cbased eGFR estimation. SDMA is the structural isomer of asymmetric dimethylarginine. A recent meta-analysis showed that plasma SDMA levels correlate with several parameters of renal function [5]. Moreover, SDMA increases rapidly after acute reduction in GFR [14]. Although there is an excellent correlation between SDMA and established estimates of GFR, it is not known if SDMA fulfils all criteria for an ideal GFR marker, that is stable production rate not affected by other diseases, free glomerular filtration and lack of tubular reabsorption [5]. Further, we lack sensitivity and specificity data for SDMA in humans. Also, the high cost of the laboratory methods to measure SDMA is still prohibitive for widespread clinical application. We therefore suggest that CKD-EPIbased eGFR should be used in adults with congenital heart disease in everyday clinical practice.

We wish to point out limitations of our study. Firstly, we did not use the gold standard for GFR measurement,
Table 1. Clinical characteristics of study population

$\begin{array}{ll}\text { Age, years } & 30.2 \pm 10.4 \\ \text { Sex, \% female } & 41.2 \\ \text { BMI } & 23.6 \pm 4.3 \\ \text { Complexity of congenital heart disease, } \% & \\ \quad \text { Simple } & 19.6 \\ \quad \text { Moderate } & 37.1 \\ \quad \text { Severe } & 43.3 \\ \text { Creatinine, } \mu \text { mol/l } & 69.6 \pm 12.0 \\ \text { Cystatin C, mg/l } & 0.69 \pm 0.15 \\ \text { SDMA, } \mu \text { mol/l } & 0.53 \pm 0.13 \\ \text { GFR, ml/min } & \\ \quad \text { Cockcroft-Gault } & 130.9 \pm 33.5 \\ \text { MDRD } & 111.0 \pm 21.1 \\ \text { Simplified MDRD } & 114.0 \pm 21.7 \\ \text { CKD-EPI } & 113.9 \pm 14.8 \\ \text { Larsson } & 129.2 \pm 26.3 \\ \text { GFR, ml/min with Larsson formula } & \\ \quad \text { NYHA I }(\mathrm{n}=56) & 132.1 \pm 19.8 \\ \quad \text { NYHA II }(\mathrm{n}=21) & 130.3 \pm 27.7 \\ \text { NYHA III (n=17) } & 124.5 \pm 38.4 \\ \text { NYHA IV (n=3) } & 95.1 \pm 26.0\end{array}$

Results are means \pm standard deviation unless otherwise stated.

that is, inulin clearance or iodthalamate clearance, but instead relied on cystatin $\mathrm{C}$ as our gold standard. However, a study in cardiac patients showed a strong correlation of cystatin C to iopromide clearance [15]. The reliability of cystatin $\mathrm{C}$ is also supported by the results of a recent meta-analysis in which it was clearly superior to creatinine as a marker of GFR [16]. In a study of 140 patients with various renal diseases, the reciprocal serum cystatin $\mathrm{C}$ level was positively correlated with inulin clearance $(r=0.882)$ [17]. A recent meta-analysis of the diagnostic accuracy of cystatin $\mathrm{C}$ for the estimation of renal dysfunction compared to inulin clearance reported that the ability of cystatin $\mathrm{C}$ to rule in renal impairment (as measured by inulin-determined GFR of $60-79 \mathrm{ml} /$ $\mathrm{min} / 1.73 \mathrm{~m}^{2}$ ) in persons in whom this is suspected is large and conclusive [18]. Further, Jonsson et al. [19] reported that estimated GFR from serum cystatin C shows strong agreement with iohexol clearance in patients with low GFR. Therefore, it is reasonable to use a cystatin C-based GFR estimation as a gold standard if inulin or iohexal clearance is not available. The second limitation of our study is the low prevalence of patients with severe renal impairment, reducing the variety, hence the spread of the different markers. Yet our patient population is the second largest in adult patients with congenital heart disease 

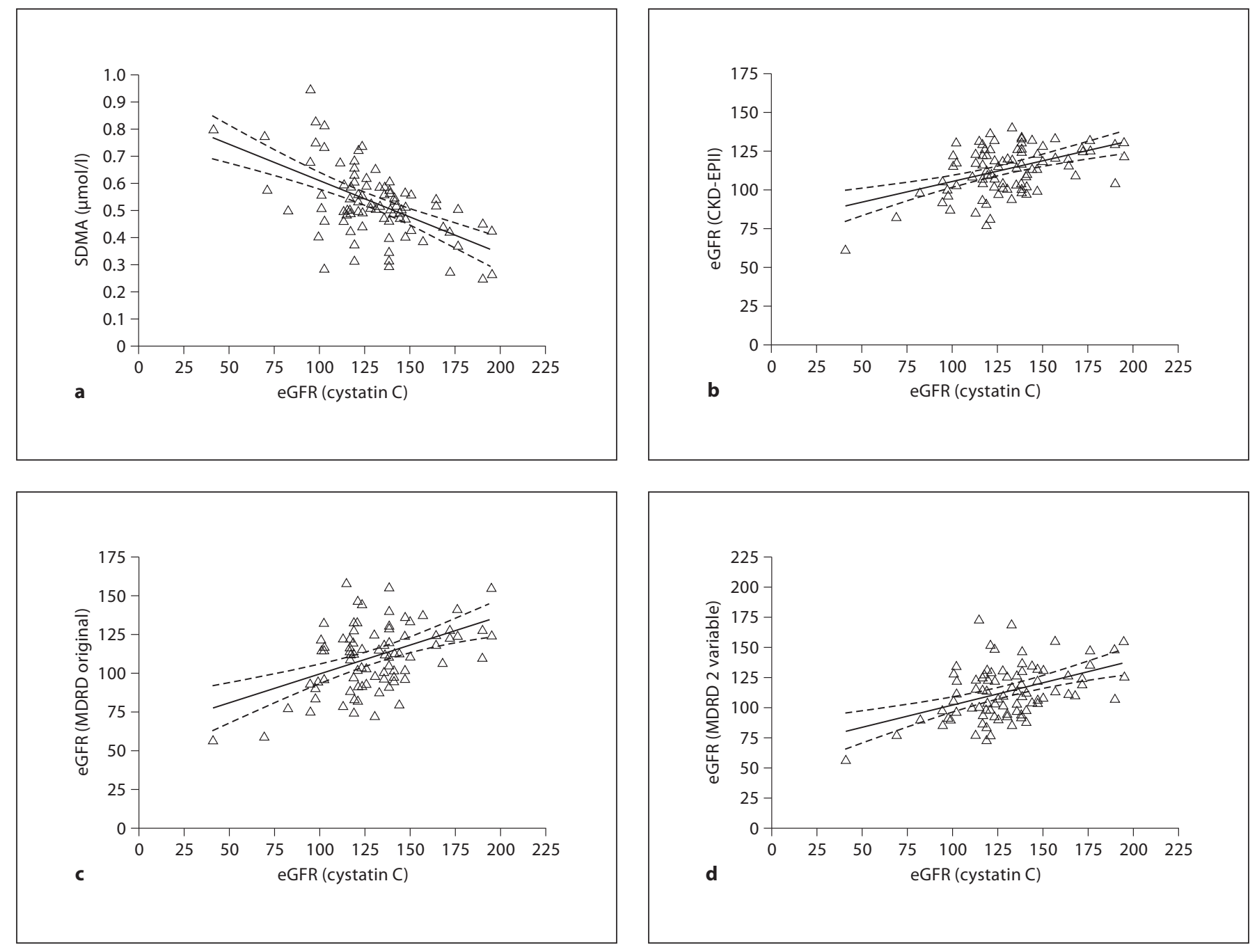

Fig. 1. Correlation of Cystatin C-based GFR with different markers and GFR equations. The strongest correlation is observed for SDMA $(r=-0.552)(a)$. GFR estimated by the CKD-EPI $(r=0.462)$ (b) and the original MDRD equation $(r=0.465)(\mathbf{c})$ show a similar strong correlation. GFR according to the simplified MDRD equation shows a slightly weaker correlation $(r=0.439)(d)$ and creatine clearance according to the Cockcroft-Gault formula shows no correlation at all $(\mathrm{r}=0.144)(\mathbf{e})$.

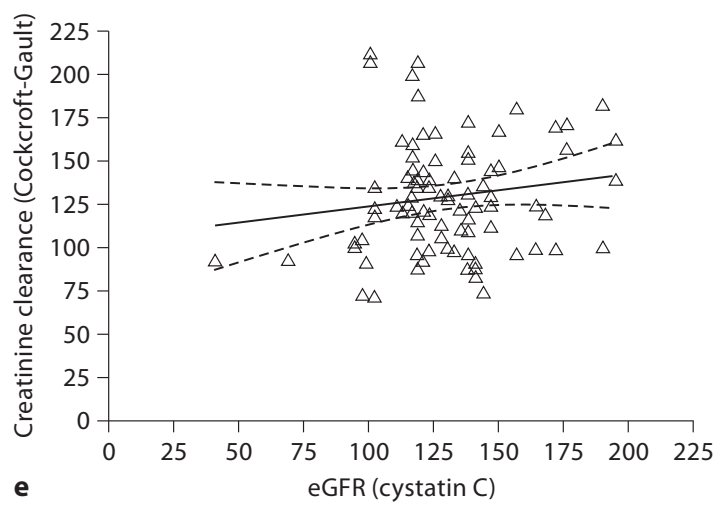


in which different parameters of renal function have been measured.

We conclude that currently in adults with congenital heart disease GFR should be estimated using the CKDEPI formula. SDMA might be a promising marker of renal function (in this patient population) that should be further evaluated.

\section{Disclosure Statement}

The authors declare no conflict of interest.

\section{References}

1 Dimopoulos K, Diller GP, Koltsida E, PijuanDomenech A, Papadopoulou SA, Babu-Narayan SV, Salukhe TV, Piepoli MF, PooleWilson PA, Best N, Francis DP, Gatzoulis MA: Prevalence, predictors, and prognostic value of renal dysfunction in adults with congenital heart disease. Circulation 2008; 117:2320-2328.

2 Kielstein JT, Martens-Lobenhoffer J, Vollmer S, Bode-Boger SM: L-arginine, ADMA, SDMA, creatinine, MDRD formula: detour to renal function testing. J Nephrol 2008;21:959-961.

-3 Levey AS, Stevens LA, Schmid CH, Zhang YL, Castro AF 3rd, Feldman HI, Kusek JW, Eggers P, Van Lente F, Greene T, Coresh J: A new equation to estimate glomerular filtration rate. Ann Intern Med 2009;150:604612.

-4 Brosius FC 3rd, Hostetter TH, Kelepouris E, Mitsnefes MM, Moe SM, Moore MA, Pennathur S, Smith GL, Wilson PW: Detection of chronic kidney disease in patients with or at increased risk of cardiovascular disease: a science advisory from the American Heart Association kidney and Cardiovascular Disease Council; the Councils on High Blood Pressure Research, Cardiovascular Disease in the Young, and Epidemiology and Prevention; and the Quality Of care and Outcomes Research Interdisciplinary Working Group: developed in collaboration with the National Kidney Foundation. Circulation 2006;114: 1083-1087.

-5 Kielstein JT, Salpeter SR, Bode-Boeger SM, Cooke JP, Fliser D: Symmetric dimethylarginine (SDMA) as endogenous marker of renal function - a meta-analysis. Nephrol Dial Transplant 2006;21:2446-2451.
6 Kakimoto Y, Akazawa S: Isolation and identification of $\mathrm{N}^{\mathrm{G}}, \mathrm{N}^{\mathrm{G}}$ - and $\mathrm{N}^{\mathrm{G}}, \mathrm{N}^{\mathrm{G}}$-dimethylarginine, n-epsilon-mono-, di-, and trimethyllysine, and glucosylgalactosyl- and galactosyl-delta-hydroxylysine from human urine. J Biol Chem 1970;245:5751-5758.

7 Kielstein JT, Fliser D, Veldink H: Asymmetric dimethylarginine and symmetric dimethylarginine: axis of evil or useful alliance? Semin Dial 2009;22:346-350.

8 Warnes CA, Liberthson R, Danielson GK, Dore A, Harris L, Hoffman JI, Somerville J, Williams RG, Webb GD: Task force 1: the changing profile of congenital heart disease in adult life. J Am Coll Cardiol 2001;37:11701175.

-9 Martens-Lobenhoffer J, Bode-Boger SM: Fast and efficient determination of arginine, symmetric dimethylarginine, and asymmetric dimethylarginine in biological fluids by hydrophilic-interaction liquid chromatography-electrospray tandem mass spectrometry. Clin Chem 2006;52:488-493.

10 Cockcroft DW, Gault MH: Prediction of creatinine clearance from serum creatinine. Nephron 1976;16:31-41.

11 Levey AS, Bosch JP, Lewis JB, Greene T, Rogers N, Roth D: A more accurate method to estimate glomerular filtration rate from serum creatinine: a new prediction equation. Modification of diet in renal disease study group. Ann Intern Med 1999;130:461-470.

12 Levey AS, Greene T, Kusek JW, Beck GJ: A simplified equation to predict glomerular filtration rate from serum creatinine. J Am Soc Nephrol 2000;11:155A.
13 Larsson A, Malm J, Grubb A, Hansson LO: Calculation of glomerular filtration rate expressed in $\mathrm{ml} / \mathrm{min}$ from plasma cystatin C values in $\mathrm{mg} / \mathrm{l}$. Scand J Clin Lab Invest 2004; 64:25-30.

14 Kielstein JT, Veldink H, Martens-Lobenhoffer J, Haller H, Burg M, Lorenzen JM, Lichtinghagen $\mathrm{R}$, Bode-Boger SM, Kliem V: SDMA is an early marker of change in GFR after living-related kidney donation. Nephrol Dial Transplant 2010; Epub ahead of print. DOI: $10.1093 / \mathrm{ndt} / \mathrm{gfq} 395$.

15 Artunc FH, Fischer IU, Risler T, Erley CM: Improved estimation of GFR by serum cystatin $\mathrm{C}$ in patients undergoing cardiac catheterization. Int J Cardiol 2005;102:173-178.

16 Dharnidharka VR, Kwon C, Stevens G: Serum cystatin $C$ is superior to serum creatinine as a marker of kidney function: a metaanalysis. Am J Kidney Dis 2002;40:221-226.

17 Nitta K, Hayashi T, Uchida K, Honda K, Tsukada M, Sekine S, Itabashi M, Yumura W, Nihei $\mathrm{H}$ : Serum cystatin $\mathrm{C}$ concentration as a marker of glomerular filtration rate in patients with various renal diseases. Intern Med 2002;41:931-935.

18 Roos JF, Doust J, Tett SE, Kirkpatrick CM: Diagnostic accuracy of cystatin C compared to serum creatinine for the estimation of renal dysfunction in adults and children - a meta-analysis. Clin Biochem 2007;40:383391.

19 Jonsson AS, Flodin M, Hansson LO, Larsson A: Estimated glomerular filtration rate (eGFRCystC) from serum cystatin C shows strong agreement with iohexol clearance in patients with low GFR. Scand J Clin Lab Invest 2007;67:801-809. 